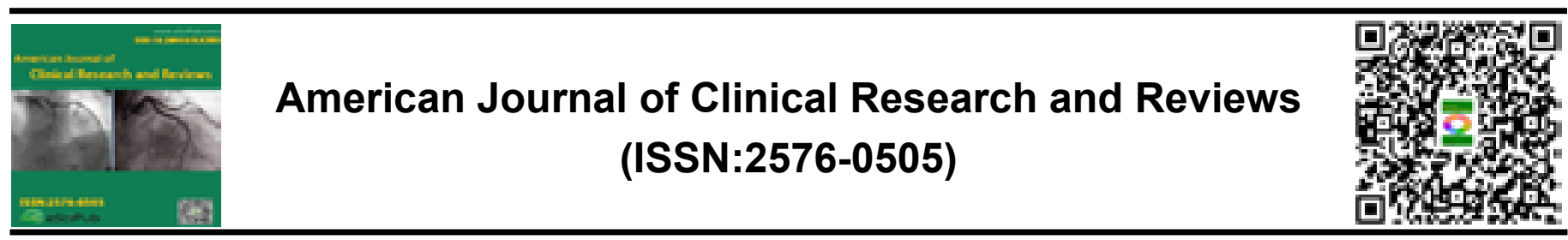

\title{
GROUP CAREGIVERS OF PEOPLE WITH DISABILITIES IN THE MUNICIPALITY OF MESSIAS ALAGOAS
}

\author{
Simone Farias dos Santos ${ }^{1 *}$, Ariana da Silva Santos ${ }^{2}$, Ana Patrícia da Santos ${ }^{3}$, Katia \\ Januário da Silva ${ }^{4}$, Manuely Janaina Lopes da Silva ${ }^{5}$, Eliane Buarque de Melo Ferreira ${ }^{6 .}$
}

\section{${ }^{123456}$ Núcleo de Apoio à Saúde da Família Secretaria Municipal de Saúde de Messias Alagoas ABSTRACT}

Introduction: In 2014, the Family Health Support Center participated in an event among children, adolescents with disabilities and their caregivers, where they receive treatment and follow-up at the Rehabilitation Center in the municipality of Messias, state of Alagoas. In this event, the mothers asked the professionals for individual and group care for them, justifying that the caregivers needed professional follow-up in the face of social and emotional overload. This year the nomenclature that was the group of mothers of children and adolescents with disabilities became a group of caregivers of people with disabilities opening inclusion for all caregivers in the municipality and also aiming at the reports of professionals from the Family Health Teams and the Center for Psychosocial Care who shared the concern with the increase in care for caregivers who have been getting ill mainly involving psychological issues. Objective: To develop actions that stimulate the strengthening and self-care in its biopsychosocial aspects, improving the quality of life and providing the consolidation of family affective bonds. Methods: This work is being carried out from the treatment of qualitative data, being an action research, descriptive and bibliographic, whose collection and collection of data occurred through conversation wheels and application of questionnaires, websites, journals and articles. Finally, it is of exploratory type, because it proceeds to provide greater familiarity with the problem that is established. Results: With the development of methods of Continuing and Permanent Education in Health, actions are practiced with strategies planned in the line of care, adding the support of the health care network so that it can be offered qualified and humanized services, thus improving the biopsychosocial and family aspects. Thus, it is remarkable that the objectives have been achieved according to shared reports and application of evaluation questionnaires in monthly meetings with caregivers. Conclusion: It is concluded that the performance strategies carried out by the work practices of the professionals of the Family Health Support Center are considered successful until today. The group remains strong and, at each meeting, new caregivers emerge. The welcoming of the authors of the group is extremely important, emphasizing that besides being humanized, it embraces each member according to their singularities and specificities.

\section{*Correspondence to Author:}

Simone Farias dos Santos

Núcleo de Apoio à Saúde da Família Secretaria Municipal de Saúde de Messias Alagoas

How to cite this article:

Simone Farias dos Santos, Ariana da Silva Santos, Ana Patrícia da Santos, Katia Januário da Silva, Manuely Janaina Lopes da Silva, Eliane Buarque de Melo Ferreira. GROUP CAREGIVERS OF PEOPLE WITH DISABILITIES IN THE MUNICIPALITY OF MESSIAS ALAGOAS. American Journal of Clinical Research and Reviews, 2020; 4:14.

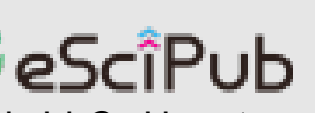

eSciPub LLC, Houston, TX USA. Website: https://escipub.com/

Keywords: caregivers, self-esteem, disability. 